\title{
Immigration and International Trade in U.S. Manufactured Goods
}

Matthew Famiglietti, Research Associate

Fernando Leibovici, Economist

$S$ ome U.S. states appear to import and export more manufactured goods than others. Might immigrant workers play a role?

Immigrants bring with them knowledge of foreign languages, markets, and customs, potentially making it easier for them to form business connections abroad and increase exports of manufactured goods. Similarly, their familiarity with foreign goods or processes might improve domestic production, increasing imports of manufactured goods. Additionally, skilled immigrants may increase the productivity of domestic firms and make domestic firms more competitive internationally, facilitating additional trade.

There might be other noncausal reasons why immigrant

\section{States with higher shares of immigrants tend to export a higher fraction of manufactured goods.}

intensity and trade intensity could be correlated, however. For instance, border states or those with coastlines might be likely to trade more internationally while also being more likely to have more foreign-born workers. The goal of this essay is to document the empirical relation between these two factors, leaving a deeper investigation into the causal nature of this relation for future work.

Thus, we ask, to what extent are the proportions of immigrants in the manufacturing workforces of U.S. states correlated with cross-state differences in international manufacturing trade?

To examine the relation between immigration and the manufacturing trade across U.S. states, Panel A of Figure 1 shows each state's implied international manufacturing trade intensity computed as follows: We add a state's exports and imports of manufactured goods, divide the sum by the state's manufacturing GDP, and then divide this measure by two. Panel B of Figure 1 shows each state's share of the manufacturing workforce born outside the United States.
We next examine the geographical dispersion in trade intensity and immigration rates in the U.S. manufacturing sector. For each state, Figure 1 illustrates the share of the manufacturing workforce born abroad and our trade intensity measure as a percentage of manufacturing GDP. The states with the largest proportions of foreign-born manufacturing workers are mostly in the Northeast, West Coast, Florida, and Texas. Similarly, many states in the Northeast, South, and Midwest are more involved in international trade, including Florida and Texas, which are heavily involved.

Figure 1 suggests that the share of foreign-born workers and the share of foreign trade in manufacturing are correlated. For example, Texas, Florida, and Nevada have high levels of both measures. States in the Northeast, Southeast, and West also have high levels of both, while states in the Great Plains have relatively low levels of both.

Figure 2 plots the two measures for each state. To highlight the correlation, we also show a (red) linear regression line and report its statistics. The correlation between the two measures is positive, economically large, and statistically significant at the 1 percent level. The slope of the bestfit line is 1.16 , which means that a 1 percent increase in the share of foreign-born manufacturing workers is associated with a 1.16 percent increase in international trade as a share of manufacturing GDP. That is, a 1-standard-deviation increase in the share of foreign-born manufacturing workers is associated with a 12.69 percent increase in international trade as a share of manufacturing GDP.

\section{Conclusion}

The shares of manufactures traded internationally and the shares of foreign-born manufacturing workers vary considerably among the 50 states. And the two measures are correlated: States with higher shares of these workers are more likely to trade more in manufactured goods. This finding may have important implications for the design of both international trade and immigration policy and for evaluating the gains from increased openness to either. 
Figure 1

The Manufacturing Trade in GDP and the Manufacturing Workforce Born Abroad

\section{A. Trade as a share of manufacturing GDP}

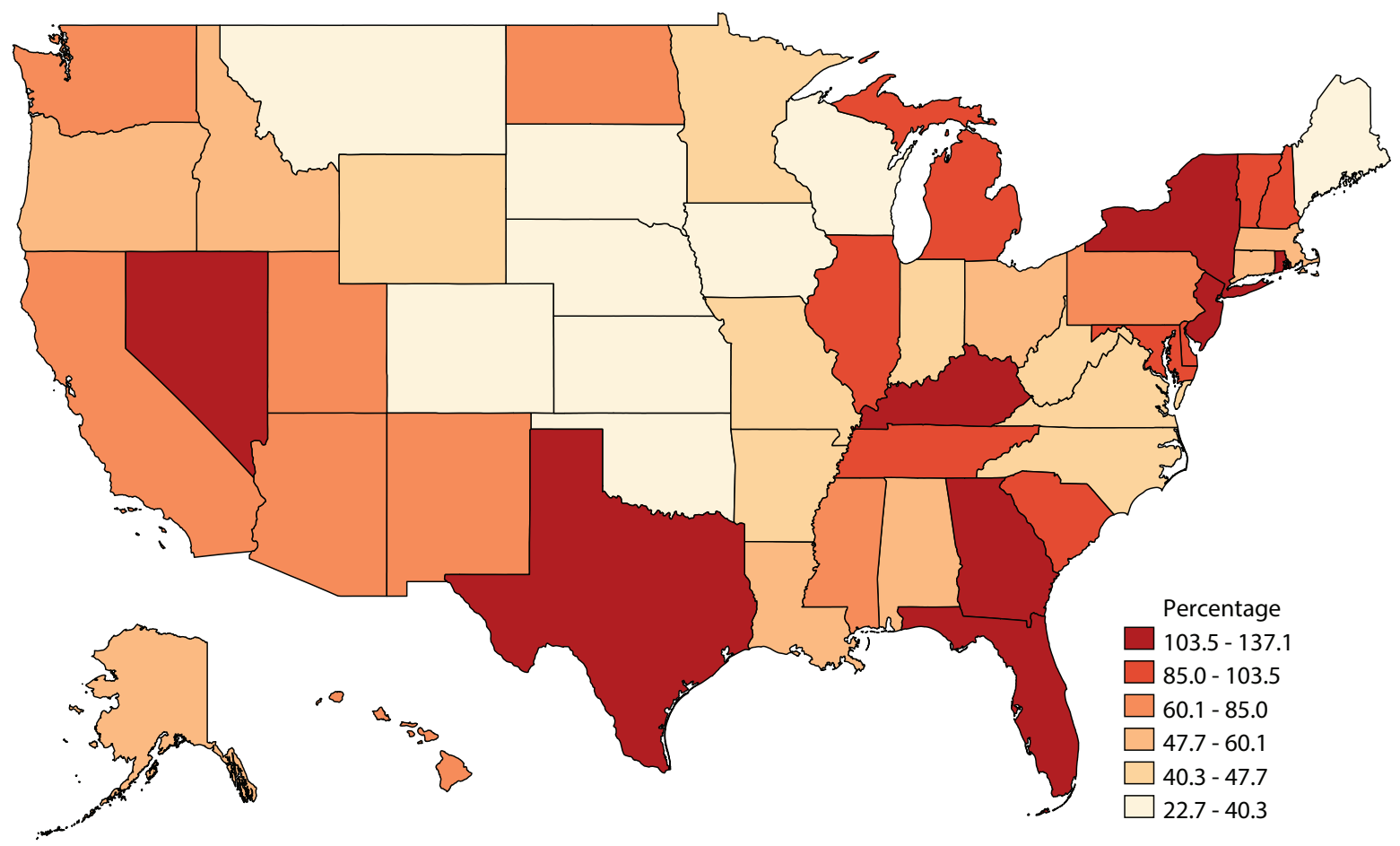

\section{B. Share of the manufacturing workforce born abroad}

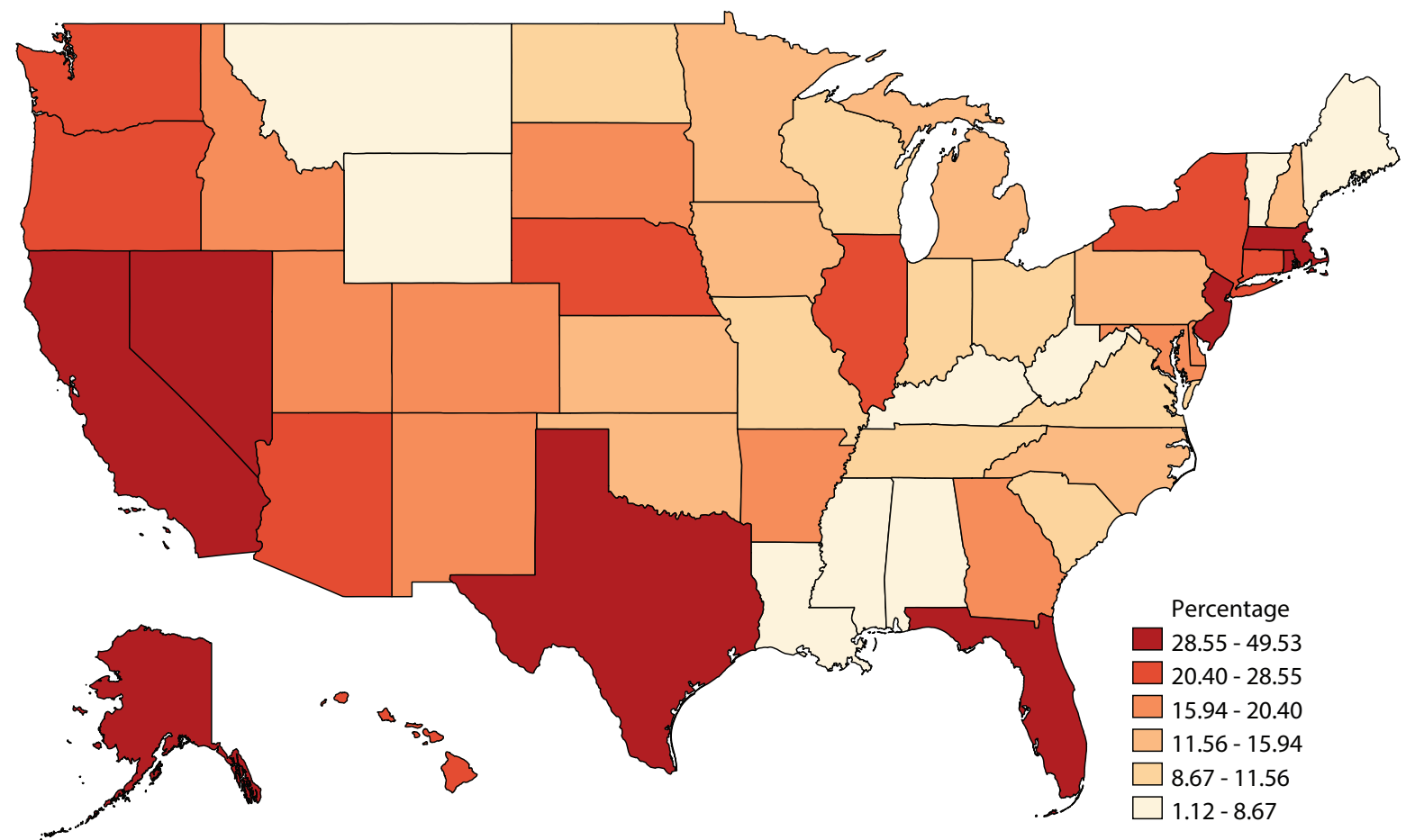

NOTE: We study individuals between 25 to 65 years of age who are in the labor force.

SOURCE: GDP data: Bureau of Economic Analysis. Trade data: U.S. Census Bureau. Workforce data: American Community Survey. One percent sample accessed from IPUMS, which provides detailed information on individuals including birthplace, industry where they work, and geographic location. 
Figure 2

The Manufacturing Trade and Immigration

Trade as share of manufacturing GDP (percent)

150

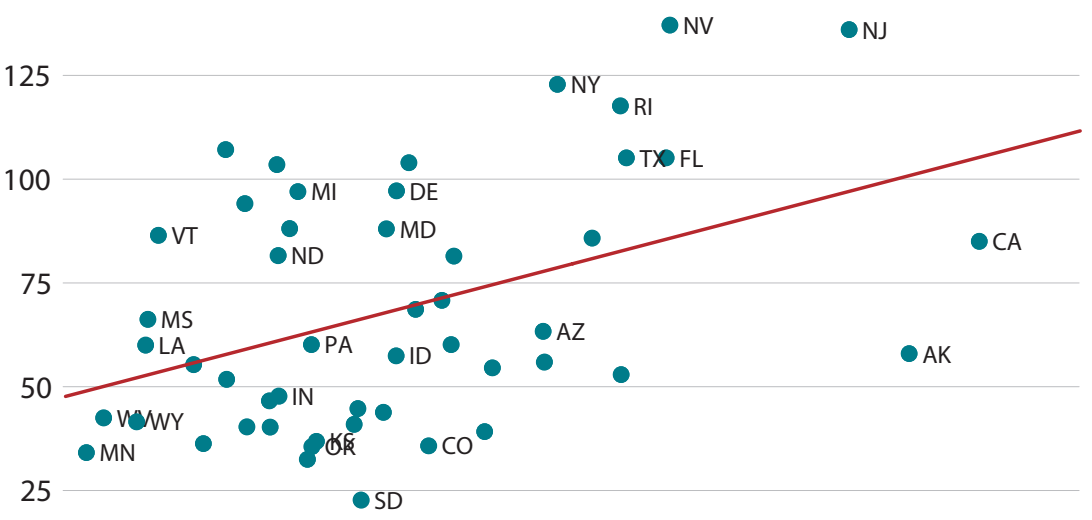

0

\begin{tabular}{llllll}
\hline 0 & 10 & 20 & 30 & 40 & 50 \\
& \multicolumn{1}{l}{ Share of manufacturing } & workforce born abroad (percent) &
\end{tabular}

trade_intensity $=47.67+1.16 *$ immigrant_share_pop $+\varepsilon, R^{2}=0.19, t$-statistic $=2.97$

NOTE: We study individuals between 25 to 65 years of age who are in the labor force.

SOURCE: GDP data: Bureau of Economic Analysis. Trade data: U.S. Census Bureau. Workforce data: American

Community Survey. One percent sample accessed from IPUMS, which provides detailed information on

individuals including birthplace, industry where they work, and geographic location. 